\title{
AVALIAÇÃO DO EFEITO DE YACON EM KEFIR SABOR MORANGO
}

\section{Evaluation of the effect of yacon in strawberry flavored kefir}

\author{
Sebastião Moreira Juniorl, Mariane Laureano Florindo de Freitas ${ }^{1}$, \\ Maurílio Lopes Martins ${ }^{1}$, Wellingta Cristina A. Nascimento Benevenuto ${ }^{1}$, \\ Isabella Fiebig Gonçalves ${ }^{l}$, Aurélia Dornelas de Oliveira Martins ${ }^{1 *}$
}

\begin{abstract}
RESUMO
Este trabalho objetivou avaliar o efeito da polpa de yacon em kefir sabor morango nas concentrações de 0, 2, 4 e 6\% de yacon e nos tempos 0,14 e 28 dias de fabricação. Quanto ao número mais provável de coliformes totais e termotolerantes as amostras do tempo 28 dias apresentaram-se conforme a legislação vigente com contagens $<3,0 \mathrm{NMP} / \mathrm{g}$. A contagem de fungos filamentosos e leveduras e bactérias láticas estavam de acordo com a legislação, para leveduras as contagens entre os tratamentos variaram de $10^{4}$ a $10^{6} \mathrm{UFC} / \mathrm{g}$. As análises físico-químicas também estavam conforme a legislação vigente, para o quesito acidez e $\mathrm{pH}$, os tratamentos variaram de 0,42 a 1,05\% de ácido lático a 4,09 a 4,65 respectivamente e na análise de cor foi verificado que a maioria das amostras não se alteraram com o passar do tempo. Produtos adicionados ou não de yacon apresentaram contagens de bactérias láticas entre 8,0 a 9,5 $\log \mathrm{UFC} / \mathrm{g}$, indicando assim que a adição de yacon não interfere no crescimento desses microrganismos. Este tubérculo não apresentou efeito prebiótico, mas por ter sido comprovado que não influenciou nas contagens de bactérias láticas, o mesmo pode ser uma boa opção para adição ao kefir, com intuito de agregar valor nutricional ao produto, uma vez que é rico em fibras.
\end{abstract}

Palavras-chave: leite fermentado; fibra; qualidade.

1 Instituto Federal de Educação, Ciência e Tecnologia do Sudeste de Minas Gerais, campus Rio Pomba, Av. Dr. José Sebastião da Paixão, Lindo Vale, 36180-000, Rio Pomba, MG, Brasil. E-mail: aurelia. dornelas@ifsudestemg.edu.br.

* Autor para correspondência. 


\begin{abstract}
This work aimed to evaluate the effect of yacon pulp on strawberry flavored kefir at 0,2, 4 and 6\% yacon concentrations and at 0,14 and 28 days of manufacture. As for the most probable number of total and thermotolerant coliforms, the samples of the time 28 days were in accordance with the current legislation, with counts $<3.0 \mathrm{MPN} / \mathrm{g}$. The count of filamentous fungi and yeasts and lactic acid bacteria were in accordance with the legislation, and for yeast counts between treatments ranged from $10^{4}$ to $10^{6} \mathrm{CFU} / \mathrm{g}$. The physicochemical analyzes were also in accordance with current legislation. For the acidity and $\mathrm{pH}$, the treatments ranged from 0.42 to $1.05 \%$ of lactic acid and 4.09 to 4.65 respectively. At the color analysis, it was verified that most of the samples did not change over time. Yacon added or not added products showed lactic acid counts between 8.0 and $9.5 \log \mathrm{CFU} / \mathrm{g}$, thus indicating that the addition of yacon does not interfere with the growth of these microorganisms. This tuber had no prebiotic effect, but because it has been proven that it did not influence lactic acid bacteria counts, it may be a good option for addition in kefir, in order to add nutritional value to the product, since it is rich in fiber.
\end{abstract}

Keywords: fermented milk; fiber; quality.

\section{INTRODUÇÃO}

A legislação brasileira define kefir como um leite fermentado resultante da fermentação de leite pasteurizado ou esterilizado realizada com cultivos ácido lácticos elaborados com grãos de kefir, Lactobacillus kefir, espécies dos gêneros Leuconostoc, Lactococcus e Acetobacter, com produção de ácido láctico, etanol e dióxido de carbono. Os grãos de kefir são constituídos também por leveduras fermentadoras de lactose e leveduras não fermentadoras de lactose (BRASIL, 2007).

O kefir é formado pela ação de uma associação de bactérias e leveduras, as quais são encapsuladas em uma matriz polissacarídica chamada "kefiran", formando os grãos de kefir. O mesmo apresenta em sua composição água, lipídeos, proteínas, carboidratos e minerais, possuem forma irregular, coloração amarelada e esbranquiçada com uma aparência semelhante à couve-flor (MACHADO et al., 2014).

Kefir é uma bebida de origem láctea obtida pelo processo de fermentação alcoólica de lática com microbiota única encontra- da em grãos de kefir. Os grãos contêm um complexo misto bacteriano produtor de ácido lático, acético, leveduras e uma matriz proteica e polissacarídeos (KESENKAS et al., 2017). É definido como um leite fermentado, ácido, levemente alcoólico, produzido de forma artesanal a partir de grãos que apresenta uma população microbiana simbiótica considerada estável, imersos em uma matriz constituída de polissacarídeos e proteínas (YOVANOUDI et al., 2013).

Segundo Machado et al (2014), o cultivo do kefir pode ser realizado por diversos tipos de substratos como leite, açúcar mascavo e suco de frutas que tem como resultado o aumento da biomassa em uma faixa de 5\% a $7 \%$ por dia.

É um leite fermentado com diversos benefícios a saúde, estando relacionada às propriedades de reparação da mucosa intestinal, redução dos sintomas de intolerância à lactose, estimulação do sistema imunológico, redução do colesterol e de propriedades tumorais (MENESTRINA et al., 2016). Este alimento pode ser consumido com diferentes produtos ricos em fibras como yacon. 
O yacon é comercializado como alimento que tem funcionalidade nutricional e farmacêutica. Tem sido descrito como o alimento com maior conteúdo de frutooligossacarídeos (FOS) na natureza, sendo uma das principais características deste carboidrato a estimulação do crescimento de bactérias não-patogênicas por meio da fermentação colônica, levando à modulação da composição do ecossistema natural do intestino grosso. Sendo classificados como constituintes bioativos com alegação prebiótica e, portanto, funcionais (VASCONCELOS; 2010).

Segundo Gusso et al. (2015) yacon e seus derivados se destacam pelo potencial prebiótico, atividade antioxidante, melhora do sistema imune e redução da glicemia. Em função dos benefícios nutricionais e funcionais que a batata yacon apresenta, a farinha dessa raiz vem sendo desenvolvida e utilizada como ingrediente em alimentos. Os autores relatam que o uso da yacon e seus derivados no desenvolvimento de novos produtos alimentícios são promissores, visto que suas propriedades funcionais estão sendo cada vez mais pesquisadas e comprovadas cientificamente.

Portanto o presente estudo teve por objetivo avaliar o efeito de diferentes concentrações de polpa de yacon em kefir sabor morango.

\section{MATERIAL E MÉTODOS}

O presente estudo foi realizado nos Laboratórios de análises físico-químicas do leite e derivados, microbiológica e de novos produtos do Departamento de Ciência e Tecnologia de Alimentos do Campus Rio Pomba.

\section{Preparo da bebida}

Para a elaboração da bebida, os grãos de kefir (obtido por doação) foram previamente cultivados em leite UHT integral adquirido no comércio local. O cultivo foi realizado adicionando-se, aproximadamente, $10 \mathrm{~g}$ de grãos de Kefir em um litro de leite, sendo este procedimento realizado em três vezes consecutivas. A bebida foi incubada a temperatura ambiente por 24 horas.

Logo após o cultivo, a bebida foi fracionada em quatro partes iguais de $250 \mathrm{~mL}$ e preparada nos seguintes tratamentos: $0 \%$ : kefir adicionado de $10 \%$ de polpa de morango; $2 \%$ : kefir adicionado de $10 \%$ de polpa de morango e $2 \%$ de polpa de yacon; $4 \%$ : kefir adicionado de $10 \%$ de polpa de morango e $4 \%$ de polpa de yacon e 6\%: kefir adicionado de $10 \%$ de polpa de morango e $6 \%$ de polpa de yacon. A polpa de morango pronta para o consumo foi adquirida em comércio local (Proregi, lote 088, data de fabricação 05/2017). O yacon foi lavado em água corrente, descascado e imerso em solução de ácido cítrico a $5 \%$ por cinco minutos com intuito de evitar o escurecimento enzimático. Logo após o tubérculo foi triturado em liquidificador e coado obtendo-se a polpa, que foi acrescida de 50\% de açúcar, homogeneizada e submetida a aquecimento até a concentração de $65^{\circ}$ Brix e armazenada a $5{ }^{\circ} \mathrm{C} \pm 1{ }^{\circ} \mathrm{C}$ para análises posteriores.

$\mathrm{O}$ experimento foi realizado em três repetições e todas as análises feitas em duplicatas.

\section{Análises microbiológicas}

Foram realizadas análises microbiológicas de coliformes totais e termotolerantes nos tempos 7 e 28 dias de armazenamento com intuito de se verificar a permanência ou redução das contagens. As análises de coliformes a $30{ }^{\circ} \mathrm{C}$ e a $45^{\circ} \mathrm{C}$ foram realizadas pela técnica do Número Mais Provável (NMP) de acordo com Kornacki; Johnson (2001), utilizando-se caldo Lauril Sulfato Triptose para o teste presuntivo, Caldo Bile Verde Brilhante para confirmar coliformes a $30{ }^{\circ} \mathrm{C}$ e caldo EC para confirmar que fermentam a $45^{\circ} \mathrm{C}$. O resultado foi expresso em NMP por grama. 
Analises de fungos filamentosos e leveduras foram realizadas segundo Beuchat; Cousin (2001) nos tempos 0, 14 e 28 dias de armazenamento.

\section{Viabilidade de bactérias láticas}

Para a contagem foram pesados $25 \mathrm{~g}$ das amostras de kefir sabor morango adicionado de polpa de yacon e logo após homogeneizadas em $225 \mathrm{~mL}$ de solução salina peptonada $(0,85 \%$ de $\mathrm{NaCl}$ e $0,1 \%$ de peptona). Posteriormente, foram realizadas diluições seriadas utilizando o plaqueamento em profundidade ou "pour plate" de $1 \mathrm{~mL}$ de cada diluição em ágar MRS (para contagem de lactobacilos) e M17 (para contagem de cocos lácteos Gram +), em placas de Petri, que foram posteriormente mantidas em jarras de anaerobiose e incubadas a $37^{\circ} \mathrm{C}$ por $72 \mathrm{~h}$. As análises foram realizadas em duplicata.

A viabilidade dos microrganismos foi determinada segundo metodologia proposta por Richter; Vedamuthu (2001), nos tempos zero, 14 e 28 dias de armazenamento, a fim de se verificar se o yacon aumentaria a viabilidade das bactérias láticas com o passar do tempo.

\section{Análises físico-químicas}

As amostras de kefir foram submetidas à determinação de acidez, pH e cor, após a fabricação dos produtos e nos tempos 0,14 e 28 dias de fabricação. Os valores de acidez titulável (\% de ácido lático) foram determinados conforme metodologia proposta pela Instrução Normativa $n^{\circ} 68$ (BRASIL, 2006). As alterações do $\mathrm{pH}$ das amostras foram monitoradas usando $\mathrm{pHmetro}$ digital (pHTek).

Também foi determinada a cor instrumental por meio da leitura das coordenadas $L^{*}, a^{*}, b^{*}$. A análise de cor instrumental foi realizada em colorímetro Konica Minolta, modelo CR-10, utilizando o sistema CIELAB (CIE, 1996).

\section{Delineamento experimental}

Foi utilizado o delineamento inteiramente casualizado, em esquema fatorial $4 \times 3$ (4 concentrações de yacon: $0,2,4$ e $6 \%$ e 3 tempos: 0, 14 e 28 dias de armazenamento) e com 3 repetições.

\section{RESULTADOS E DISCUSSÃO}

\section{Qualidade microbiológica das amostras}

O número mais provável de coliformes totais e termotolerantes reduziu ao longo do tempo de armazenamento (Tabela 1), sendo que para coliformes totais a legislação preconiza no máximo $100 \mathrm{NMP} / g$ e coliformes termotolerantes preconiza no máximo $10 \mathrm{NMP} / \mathrm{g}$ (BRASIL, 2007). Conforme essa legislação, as amostras com 7 dias de fabricação estavam em desacordo com os padrões, e no tempo 28 dias estavam conforme, atingindo níveis aceitáveis.

A redução na contagem de coliformes provavelmente se deve ao aumento na acidez do produto causado pela produção de ácido pelas bactérias encontradas nos grãos de kefir.

O processo de fermentação transforma as características do leite e diminui o desenvolvimento de bactérias e microrganismos deteriorantes e patogênicas o que aumenta o tempo de conservação do produto (CARNEIRO et al., 2012), o que foi observado no presente estudo em que com 28 dias o kefir estava apto ao consumo. Vale ressaltar que no Brasil o kefir é obtido por doação, provavelmente o que acarretou contagens de coliformes totais e termotolerantes superiores ao estabelecidos pela legislação vigente ao $7^{\circ}$ dia de armazenamento.

Segundo Piard et al. (1999), bactérias produtoras de ácido lático tem a função de acidificar os alimentos em pH próximo de 4 . 
O ácido lático, por ser orgânico e de cadeia curta, impede o crescimento de contaminantes.

Quanto à contagem de fungos filamentosos e leveduras, a Instrução Normativa $n^{\circ} 46$, de 23 de outubro de 2007 estabelece uma contagem mínima de $10^{4} \mathrm{UFC} / \mathrm{g}$, sendo as amostras avaliadas estavam conforme a legislação vigente, uma vez que os resultados variaram de $10^{4}$ a $10^{6} \mathrm{UFC} / \mathrm{g}$ (Tabela 2). Como o kefir é constituído por leveduras fermentadoras de lactose e leveduras não fermentadoras de lactose (BRASIL, 2007) esperavamse contagens acima do mínimo exigido pela legislação.

Resultados conforme a legislação para fungos filamentosos e leveduras também foram encontrados por Lima et al. (2014) ao avaliarem leite de ovelha fermentado por kefir. Os autores encontraram no primeiro dia de armazenamento $8 \mathrm{logs} \mathrm{UFC} / \mathrm{mL}$ de fungos filamentosos e leveduras, e no final de 28 dias de estocagem, o valor reduziu para 6,6 $\log \mathrm{UFC} / \mathrm{mL}$, portanto em todos os tempos os valores foram superiores a $4 \log \mathrm{UFC} / \mathrm{mL}$ conforme estabelece o Regulamento Técnico de Identidade e Qualidade de Leites Fermentados (BRASIL, 2007).

\section{Viabilidade de bactérias láticas}

Entre os tratamentos não houve diferença significativa $(\mathrm{p}>0,05)$ na contagem de lactobacilos e cocos láticos Gram +. O tempo de armazenamento também não interferiu na contagem $(p>0,05)$ desses microrganismos. Portanto, a adição do yacon não interferiu na viabilidade de bactérias láticas presentes no kefir.

As contagens no ágar MRS (Lactobacillus) das diferentes amostras (Figura 1)

Tabela 1 - Análises de coliformes totais e termotolerantes (NMP/g) nas amostras de kefir sabor morango com yacon com 7 e 28 dias de armazenamento

\begin{tabular}{ccccc}
\hline \multirow{2}{*}{ Amostras } & \multicolumn{2}{c}{ Coliformes Totais } & \multicolumn{2}{c}{ Coliformes Termotolerantes } \\
\cline { 2 - 5 } & \multicolumn{2}{c}{$(\mathrm{NMP} / \mathrm{g})$} & \multicolumn{2}{c}{$(\mathrm{NMP} / \mathrm{g})$} \\
\cline { 2 - 5 } & $>1100$ & $<3$ dias & 28 dias \\
\hline Controle & $>1100$ & $<3,0$ & $>1100$ & $<3,0$ \\
Kefir com $2 \%$ de yacon & $>1100$ & $<3,0$ & $>1100$ & $<3,0$ \\
Kefir com 4\% de yacon & $>1100$ & $<3,0$ & $>1100$ & $<3,0$ \\
Kefir com 6\% de yacon & & & & $<3,0$ \\
\hline
\end{tabular}

Tabela 2 - Contagem de fungos filamentosos e leveduras (UFC/g) em amostras de kefir sabor morango com yacon nos tempos 0,14 e 28 dias de armazenamento

\begin{tabular}{cccc}
\hline \multirow{2}{*}{ Tratamentos } & \multicolumn{3}{c}{ Tempo (dias) } \\
\cline { 2 - 4 } & 0 Dias & 14 Dias & 28 Dias \\
\hline Controle & $3,2 \times 10^{5}$ & $9,6 \times 10^{6}$ & $1,8 \times 10^{5}$ \\
Kefir com $\%$ de yacon & $4,7 \times 10^{5}$ & $6,4 \times 10^{6}$ & $1,1 \times 10^{5}$ \\
Kefir com 4\% de yacon & $3,2 \times 10^{5}$ & $1,2 \times 10^{6}$ & $1,3 \times 10^{5}$ \\
Kefir com 6\% de yacon & $3,8 \times 10^{5}$ & $1,2 \times 10^{6}$ & $5,4 \times 10^{4}$ \\
\hline
\end{tabular}


variaram de 8,5 a 9,15 log UFC nos diferentes tempos, indicando que a adição do yacon não interferiu na viabilidade desses microrganismos presentes no kefir.

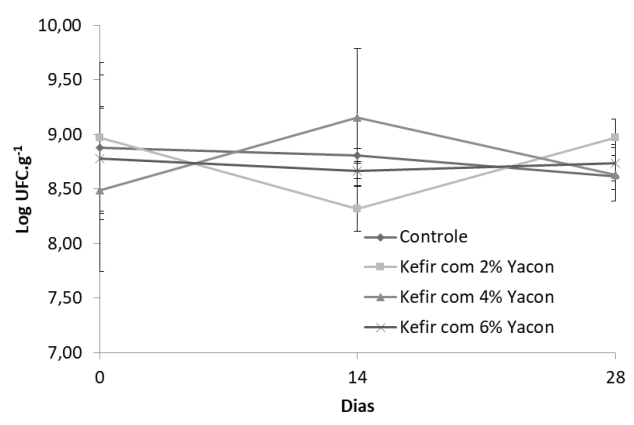

Figura 1 - Viabilidade de bactérias láticas no kefir avaliadas em meio ágar MRS.

As contagens no ágar M17 (cocos láticos Gram +) das diferentes amostras (Figura 2) variaram de 8,32 a 9,15 log UFC nos diferentes tempos, indicando que a adição do yacon não interferiu na viabilidade deste grupo de microrganismos presente no kefir.

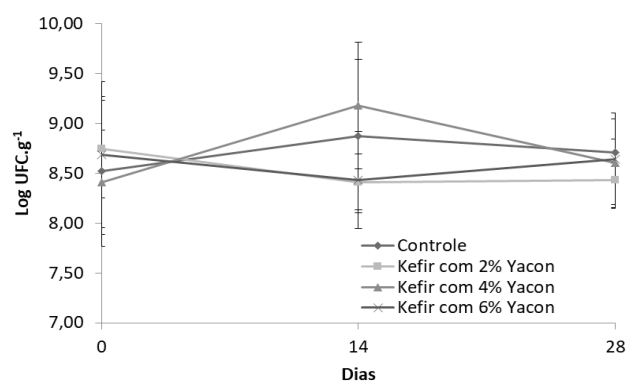

Figura 2 - Viabilidade de bactérias láticas no kefir avaliadas em meio ágar M17.

Em comparação com a legislação todas as amostras se encontram dentro dos padrões, que estabelece contagem de bactérias láticas acima de $10^{7} \mathrm{UFC} / \mathrm{mL}$ (BRASIL, 2007).

Resultados semelhantes foram encontrados por Santos (2012) no qual realizou avaliação microbiológica de leite fermentado com grãos de kefir, e encontrou em seus estudos contagem para bactérias lácticas variando entre $1,4 \times 10^{8}$ a $3,8 \times 10^{9} \mathrm{UFC} / \mathrm{mL}$.

Diversos microrganismos estão associados ao kefir brasileiro. Por meio da utilização de uma combinação de fenotípicos e genotípicos, foram encontrados diversas variedades de isolados microbianos, entre eles foram identificados bactérias do ácido láctico, leveduras e bactérias do ácido acético. Lactobacillus paracasei, Lactobacillus parabuchneri, Lactobacillus casei, Lactobacillus kefir, Lactococcus lactis foram espécies microbianas isoladas dos grãos de kefir brasileiro (MAGALHÃES et al, 2011).

Quanto à viabilidade avaliada em ágar M17 (Figura 2), foi observado variação na contagem de 8,0 a 9,5 ciclos log UFC ao longo dos dias. Porém, é importante ressaltar que no tempo de 14 dias de armazenamento as amostras com $4 \%$ de yacon apresentaram um aumento em sua contagem, efeito contrário ocorreu com as amostras com $2 \%$ e $6 \%$ de adição do tubérculo. E no tempo de 28 dias todas as amostras apresentaram contagem de cocos láticos Gram + próximas à contagem inicial. Sendo que, todas as amostras apresentaram valores dentro do estabelecido pela legislação vigente (BRASIL, 2007). Como no Kefir são encontrados tanto lactobacilos quanto cocos láticos Gram +, o uso de MRS e M17 faz-se necessário para quantificar ambos os grupos de microrganismos.

Resultados semelhantes foram encontrados para leites fermentados ao longo dos 18 dias de armazenamento, os resultados demonstraram que nas condições estabelecidas obteve-se um produto que manteve o número mínimo de bactérias láticas totais estabelecido no Regulamento Técnico de Identidades e Qualidade dos leites fermentados (MONTEIRO, 2014).

Comparando os dois gráficos obtidos, observa-se que a contagem de lactococos e lactobacilos foram semelhantes para todos os tratamentos. Gronnevik et al. (2011) avaliaram 
contagem de lactococos e lactobacilos em amostras de kefir nos tempos 0, 7, 14, 21 e 28 dias de armazenamento e verificaram que a população de lactobacilos foi maior do início ao fim do período de armazenamento.

Em estudo realizado por Rossetto (2015), onde foi verificada a viabilidade do uso de bactérias lácticas em diferentes marcas comercializadas de leite fermentado, observou-se que todas as amostras avaliadas apresentaram redução do número de bactérias lácticas viáveis, entretanto todas ficaram conforme o estabelecido pela legislação vigente.

\section{Análises físico-químicas}

Para o parâmetro acidez, em cada tempo avaliado $(0,14$ e 28 dias $)$ os tratamentos não diferiram entre si $(\mathrm{p}>0,05)$. As amostras com $0 \%$ e $4 \%$ de yacon (Tabela 3 ), tiveram maiores valores de acidez no tempo 28 quando comparado ao tempo 0 . Em relação ao adicionado de $2 \%$ pode-se verificar que houve diferença significativa $(\mathrm{p}<0,05)$ no tempo 0 , devido a uma redução da acidez. Já para o tratamento com $6 \%$ foi verificado diferença significativa $(\mathrm{p}<0,05)$ entre o tempo 28 e os demais tempos analisados. Todas as amostras estão conforme a legislação vigente estabelecida por Brasil (2007).

Valores baixos de acidez podem ser a causa do desenvolvimento de microrganis- mo indesejável em produtos fermentados, como os patogênicos. No entanto, a elevação da acidez pode causar modificações nas características sensoriais do produto, além de torná-lo incompatível com as características de identidade estabelecidas pela legislação vigente (EMILIANO et al., 2017). É valido destacar que devido ao aumento da acidez nos produtos com yacon do tempo 0 para o tempo 28 dias de armazenamento, a avaliação sensorial do produto seria um fator importante a ser avaliado em estudos posteriores.

Não houve diferença entre os tratamentos $(\mathrm{p}>0.05)$ para os valores de $\mathrm{pH}$ nos tempos 0 e 14 dias (Tabela 4). Entretanto, no tempo 28 o controle apresentou maior valor $(\mathrm{p}<0,05)$ quando comparado ao tratamento com $4 \%$ de yacon.

Os tratamentos controle, com $2 \%$ e $6 \%$ de yacon apresentaram menores valores de $\mathrm{pH}(\mathrm{p}<0,05)$ após 14 dias de armazenamento mantendo-se constante até o final do período analisado. O kefir elaborado com 4\% de yacon apresentou decréscimo nos valores de $\mathrm{pH}(\mathrm{p}<0,05)$ ao longo de todo período analisado.

Os valores de $\mathrm{pH}$ das amostras variam de 4,09 a 4,65. Uma redução de pH é esperada em produtos lácteos fermentados, durante o período de armazenamento, já que o nível de acidez está inversamente relacionado com o valor de pH (MEIRA et al., 2015).

Tabela 3 - Valores médios de acidez (\% de ácido lático) de amostras de kefir sabor morango com yacon nos tempos 0,14 e 28 dias de armazenamento

\begin{tabular}{cccc}
\hline \multirow{2}{*}{ Tratamentos } & \multicolumn{3}{c}{ Tempo (dias) } \\
\cline { 2 - 4 } & 0 Dias & 14 Dias & 28 Dias \\
\hline Controle & $0,62 \pm 0,10^{\mathrm{B}}$ & $0,81 \pm 0,14^{\mathrm{AB}}$ & $0,89 \pm 0,04^{\mathrm{A}}$ \\
Kefir com 2\% de yacon & $0,42 \pm 0,18^{\mathrm{B}}$ & $0,82 \pm 0,18^{\mathrm{A}}$ & $1,02 \pm 0,05^{\mathrm{A}}$ \\
Kefir com 4\% de yacon & $0,62 \pm 0,10^{\mathrm{B}}$ & $0,81 \pm 0,03^{\mathrm{AB}}$ & $0,95 \pm 0,11^{\mathrm{A}}$ \\
Kefir com 6\% de yacon & $0,58 \pm 0,09^{\mathrm{B}}$ & $0,78 \pm 0,01^{\mathrm{B}}$ & $1,05 \pm 0,07^{\mathrm{A}}$ \\
\hline
\end{tabular}

Médias seguidas pela mesma letra na linha não diferem entre si ao nível de $5 \%$ de significância pelo teste de Tukey. 
Tabela 4 - Valores médios de $\mathrm{pH}$ das amostras de kefir sabor morango com yacon nos tempos 0,14 e 28 dias de armazenamento

\begin{tabular}{cccc}
\hline \multirow{2}{*}{ Tratamentos } & \multicolumn{3}{c}{ Tempo (dias) } \\
\cline { 2 - 4 } & 0 Dias & 14 Dias & 28 Dias \\
\hline Controle & $4,65 \pm 0,26^{\mathrm{Aa}}$ & $4,46 \pm 0,09^{\mathrm{Ba}}$ & $4,32 \pm 0,01^{\mathrm{Ba}}$ \\
Kefir com $\%$ de yacon & $4,61 \pm 0,27^{\mathrm{Aa}}$ & $4,33 \pm 0,17^{\mathrm{Ba}}$ & $4,12 \pm 0,10^{\mathrm{Bab}}$ \\
Kefir com 4\% de yacon & $4,58 \pm 0,20^{\mathrm{Aa}}$ & $4,30 \pm 0,15^{\mathrm{Ba}}$ & $4,09 \pm 0,03^{\mathrm{Cb}}$ \\
Kefir com 6\% de yacon & $4,60 \pm 0,17^{\mathrm{Aa}}$ & $4,31 \pm 0,16^{\mathrm{Ba}}$ & $4,17 \pm 0,03^{\mathrm{Bab}}$ \\
\hline
\end{tabular}

Médias seguidas pela mesma letra minúscula nas colunas e maiúscula nas linhas, não diferem entre si ao nível de 5\% de significância pelo teste de Tukey.

Tabela 5 - Análise de cor de kefir adicionado de diferentes concentrações de yacon nos tempos 0,14 e 28 dias de armazenamento

\begin{tabular}{cccc}
\hline \multirow{2}{*}{ Tratamentos } & \multicolumn{3}{c}{ Tempo (dias) } \\
\cline { 2 - 4 } & 0 Dias & $\mathbf{1 4}$ Dias & 28 Dias \\
\hline a (verde (-) / vermelho (+)) & & & \\
Controle & $7,96^{\mathrm{a}}$ & $28,31^{\mathrm{a}}$ & $28,50^{\mathrm{a}}$ \\
Kefir com 2\% de yacon & $6,26^{\mathrm{a}}$ & $27,46^{\mathrm{a}}$ & $27,13^{\mathrm{a}}$ \\
Kefir com 4\% de yacon & $8,13^{\mathrm{a}}$ & $27,71^{\mathrm{a}}$ & $23,49^{\mathrm{a}}$ \\
Kefir com 6\% de yacon & $5,01^{\mathrm{a}}$ & $5,11^{\mathrm{a}}$ & $24,37^{\mathrm{a}}$ \\
\hline b (azul (-) / amarelo (+)) & & & \\
Controle & $-1,15^{\mathrm{b}}$ & $2,16^{\mathrm{ab}}$ & $4,71^{\mathrm{a}}$ \\
Kefir com 2\% de yacon & $-0,95^{\mathrm{a}}$ & $3,68^{\mathrm{a}}$ & $-1,80^{\mathrm{a}}$ \\
Kefir com 4\% de yacon & $2,20^{\mathrm{a}}$ & $3,01^{\mathrm{a}}$ & $1,97^{\mathrm{a}}$ \\
Kefir com 6\% de yacon & $3,03^{\mathrm{a}}$ & $2,63^{\mathrm{a}}$ & $2,89^{\mathrm{a}}$ \\
\hline L (Luminosidade) & & & \\
Controle & $52,62^{\mathrm{a}}$ & $34,28^{\mathrm{a}}$ & $30,13^{\mathrm{a}}$ \\
Kefir com 2\% de yacon & $44,00^{\mathrm{a}}$ & $28,91^{\mathrm{a}}$ & $25,39^{\mathrm{a}}$ \\
Kefir com 4\% de yacon & $48,99^{\mathrm{a}}$ & $26,56^{\mathrm{a}}$ & $24,14^{\mathrm{a}}$ \\
Kefir com 6\% de yacon & $48,69^{\mathrm{a}}$ & $29,51^{\mathrm{a}}$ & $23,93^{\mathrm{a}}$ \\
\hline
\end{tabular}

Médias seguidas pela mesma letra nas linhas não diferem entre si ao nível de $5 \%$ de significância pelo teste de Tukey. 
Valores diferentes foram encontrados por PALLEZI et al. (2015). Segundo os pesquisadores as medidas de $\mathrm{pH}$ realizadas no kefir mostrou que não houve diferença nos resultados durante o período analisado, encontrando um valor médio para o $\mathrm{pH}$ de 4,75 no kefir de leite e de 4,75 para o de água.

Estudo feito por Caetano; Montanhini (2014), avaliou o kefir em diferentes temperaturas de fermentações e obteve uma média de $\mathrm{pH}$ variando de 3,25 a 4,24, além disso os autores descrevem que o $\mathrm{pH}$ baixo representa um fator intrínseco inibitório para muitos microrganismos, o que seria favorável em se tratando do efeito antimicrobiano do produto frente às bactérias patogênicas.

Quanto à análise de cor (Tabela 5), não foi verificado diferença significativa $(p>0,05)$ dos parâmetros avaliados entre as amostras no mesmo tempo (coluna). Também não foi verificado diferença significativa $(\mathrm{p}>0,05)$ para todas as amostras em relação aos parâmetros a (coordenada de acromaticidade verde (-) / vermelho(+)) e L (Luminosidade) durante o tempo de armazenamento (linha).

Quanto ao parâmetro b (coordenada de cromaticidade azul (-) /amarelo (+) ), somente o tratamento controle apresentou diferença significativa $(\mathrm{p}<0,05)$ com 28 dias, o que significa que no tempo 28, a amostra está tendendo para uma coloração amarela. As amostras adicionadas de yacon não diferiram ao longo do tempo, indicando que o yacon mantem a coloração do produto em relação ao parâmetro b.

\section{CONCLUSÕES}

Todas as amostras se encontram de acordo com os padrões estabelecidos pela legislação para bactérias láticas, fungos filamentosos e leveduras. Apesar do yacon não apresentar efeito prebiótico, o mesmo não influenciou negativamente no crescimento das bactérias láticas do kefir, podendo ser uma boa opção para ser adicionado ao produto, uma vez que é rico em fibras. Diante dos resultados da acidez, é importante ressaltar a importância da análise sensorial para verificar a aceitabilidade dos produtos pelos consumidores, o que poderá ser realizado em estudos posteriores.

Ressalta-se ainda a importância de se verificar a origem do kefir para que o mesmo não apresente risco à saúde do consumidor, uma vez que no presente estudo as amostras, logo que adquiridas, estavam em desacordo com a legislação vigente para coliformes totais e termotolerantes.

\section{REFERÊNCIAS}

BEUCHAT, L. R.; COUSIN, M. A. Yeasts and Molds. In: DOWNES, F. P; ITO, K. (Ed.). Compendium of Methods for the Microbiological Examination of Foods. $4^{\mathrm{a}}$ ed. Washington, DC: American Public Health Association - APHA, 2001. p. 209 215.

BRASIL. Ministério da Agricultura, Pecuária e Abastecimento. Instrução Normativa n⿳o 68 , de 12 de dezembro de 2006. Oficializa os métodos analíticos oficiais físico-químicos, para controle de leite e produtos lácteos. Diário Oficial da República Federativa do Brasil, Brasília, 14 dez. 2006. Seção 1, p. 8.

BRASIL. Ministério da Agricultura, Pecuária e Abastecimento. Instrução Normativa $\mathrm{n}^{\mathrm{o}} 46$ de 23 de outubro de 2007. Adota o Regulamento Técnico de Identidade e Qualidade de Leites Fermentados. Diário Oficial da República Federativa do Brasil, Brasília, 24 out. 2007, Seção 1.

CAETANO, D. R.; MONTANHINI, M. T. M. Análise microbiológica de leite fermentado kefir produzido com leite contaminado por Escherichia coli. Revista Brasileira de Pesquisa em Alimentos, v. 5, n. 1, p. 33-38, 2014. 
CARNEIRO, C. S. et al. Leites fermentados: histórico, composição, características físico químicas, tecnologia de processamento e defeitos. Pubvet, v. 6, n. 27, p.1423-1428, 2012.

CIE - Commission Internationale de l'Éclairage. Colorimetry. Vienna: CIE publication, $2^{\mathrm{a}}$ ed. 1996.

EMILIANO, J. V. S. et al. Avaliação físico-química e microbiológica de iogurtes comercializados em Rio Pomba-MG e comparação com os parâmetros da legislação. Revista Vertice, v. 19, n. 1, 2017.

GRONNEVIK, H.; FALSTAD, M.; NARVHUS, J. A. Microbiological and chemical properties of Norwegian kefir during storage. International Dairy Journal, v. 21, p. 601-606, 2011.

GUSSO, A. P.; MATTANNA, P.; RICHARDS, N. Yacon: benefícios à saúde e aplicações tecnológicas. Ciência Rural, v. 45, n. 5, p. 912-919, 2015.

KESENKAS, H.; GURSOY, O.; OZBAR, O. kefir. Fermented Foods in Health and Disease Prevention, 2017, p. 339-361.

KORNACKI, J. L.; JOHNSON, J. L. Enterobacteriaceae, coliforms, and Escherichia coli as quality and safety indicators. Compendium of Methods for the Microbiological Examination of Foods. $4^{\mathrm{a}}$ ed. Washington: American Public Health Association - APHA, 2001. p. 69-82.

LIMA, M. et al. Características Microbiológicas e Antioxidantes de um Novo Alimento Funcional Probiótico: Leite de Ovelha Fermentado por Kefir. In: CONGRESSO BRASILEIRO DE ENGENHARIA QUÍMICA, 20., 2014. Anais eletrônicos... COBEQ: Florianópolis, 2014. Disponível em: $<$ http:// www.proceedings.blucher.com.br/articledetails/caractersticas-microbiolgicas-eantioxidantes-de-um-novo-alimento-funcionalprobitico-leite-de-ovelha-fermentado-porkefir-17081>. Acesso em: 5 mar. 2018.

MACHADO, B. A. et al. Mapeamento tecnológico de patentes de kefir. Cadernos de Prospecção, v. 5, n. 2, p. 86, 2014.

MAGALHÃES, K. T. et al. Brazilian kefir: structure, microbial communities and chemical composition. Brazilian Journal of Microbiology, v. 42, n. 2, p. 693-702, 2011.

MEIRA, Q. G. S. et al. Effects of added Lactobacillus acidophilus and Bifidobacterium lactis probiotics on the quality characteristics of goat ricotta and their survival under simulated gastrointestinal conditions. Food Research International, v. 76, p. 1-47, 2015.

MENESTRINA，F; GRISALES，J. O; CASTELLS, C. B. Chiral analysis of derivatized amino acids from kefir by gas chromatography. Microchemical Journal, v. 128, p. 267-273, 2016 .

MONTEIRO, P. D. L. Contagem de bactérias láticas em leite fermentado kefir. In: SALÃO DE INICIAÇÃO CIENTÍFICA, 16., 2014, Porto Alegre. Anais eletrônicos... UFRGS: Porto Alegre, 2014. Disponível em: <https:// www.lume.ufrgs.br/handle/10183/113669>. Acesso em: 03 mar. 2018.

PALLEZI, S. C; DE MARCHI, L; PIETTA, G. M. Caracterização e avaliação sensorial do kefir tradicional e derivados. Unoesc \& Ciência-ACET, edição especial, p. 15-22, 2015.

PIARD, J. C.; LE LOIR, Y.; POQUET, I.; LANGELLA, P. Bactérias láticas: as bactérias 
lácteas no centro de novos desafios tecnológicos. Biotecnologia Ciência e Desenvolvimento, encarte especial, p. 80-88, 1999.

RICHTER, R. L.; VEDAMUTHU, E. R. Milk and milk products. In: DOWNES, F. P.; ITO, K. (Ed.). Compedium of Methods for the Microbiological Examination of Foods. $4^{\mathrm{a}}$ ed. Washington, DC: American Public Health Association - APHA, 2001. p. 483-496

ROSSETTO, B. T. Viabilidade do uso de bactérias lácticas em marcas comercializadas de leite fermentado. 2015.51 p. Trabalho de Conclusão de Curso (Bacharelado em Química) - Universidade Tecnológica Federal do Paraná, Pato Branco, 2015.
SANTOS, A. V. D. Desenvolvimento de produtos lácteos fermentados por grãos de kefir com teor de colesterol reduzido e saborizados com frutas tropicais. 2012. 130 p. Tese (Doutorado em Engenharia de Processos) - Universidade de Tiradentes, Aracaju, 2012.

VASCONCELOS, C. M. et al. Determinação da fração da fibra alimentar solúvel em raiz e farinha de yacon (Smallanthus sonchifolius) pelo método enzimático-gravimétrico e cromatografia líquida de alta eficiência. Revista do Instituto Adolfo Lutz, v. 69, n. 2 , p. 188-193, 2010.

YOVANOUDI, M. et al. Flow behavior studies of kefir type systems. Journal of Food Engineering, v. 118, n. 1, p. 4148, 2013. 